\title{
Numerical Determination of Sheet Metal Formability under Simultaneous Stretching and Bending
}

\author{
A. Martinez-Lopez ${ }^{\mathrm{a}, \mathrm{b}}$ and A.H. van den Boogaard ${ }^{\mathrm{b}}$ \\ ${ }^{a}$ Materials innovation institute (M2i), \\ P.O. Box 5008, 2600 GA Delft, The Netherlands. \\ ${ }^{b}$ University of Twente, Faculty of Engineering Technology, Applied Mechanics \\ Postbus 217, 7500 AE, Esnchede, The Netherlands.
}

\begin{abstract}
The plastic behavior of AHSS is still far from being completely understood, and its prediction is of large importance in reliability of forming simulation in present automotive industry [1]. Conventional techniques have been proven to be not accurate enough, and underestimate the formability limits for AHSS materials in cases where stretching and bending are combined. In order to satisfy industrial requirements more work need to be done to understand the formability behavior of sheet metal, and special attention needs to be directed to the possible reasons of the lower predicted formability limits. In previous work [2], experimental results for different materials confirmed the positive effect of bending in terms of formability, and demonstrated the influence of curvature on the FLC is especially clear in the plane strain region. Using conventionally determined FLC could lead to not optimal material consumption during sheet forming operations. For this reason, in this study 3D Finite Element simulations were developed using the commercial code ABAQUS/Standard to investigate further the effect of the out of plane stress, and punch radii for the FLC determination. Also the investigation of the influence of different lubrication systems was accomplished.
\end{abstract}

Keywords: plastic forming, forming limit curve, bending.

PACS: $81.20 . \mathrm{Hy}$, 81.05.Bx, 62.20.Fe

\section{INTRODUCTION}

In order to fulfill new environmental regulations to reduce emissions of Greenhouse Gas (GHG), new grades of Advanced High-Strength Steel (AHSS) have for a large part replaced conventional steels for vehicle's body structures. These changes are intended to reduce total vehicle weight and increase fuel efficiency. However, the implementation of these materials brought new challenges to predict the material response under sheet metal operations. It is known that sheet metal can only be deformed to a certain level before local necking, and subsequently failure occurs. The forming limit curve (FLC) or forming limit diagram (FLD) is a very common tool to determine the maximum principal strains that can be sustained by sheet materials prior to the onset of localized necking. However, the validity is limited to certain conditions, such as, regions with low curvatures, proportional deformations, in-plane stresses only, and the absence of bending, among others. Some of the first studies in relation to the influence of curvature during forming operations were realized by 
Ghosh and Hecker [3]. After analyzing data from an in-plane stretching test, with experimental results from a Nakazima type test, they determined that the formability of a metal sheet was positively influenced by the constrained deformation in contact with the rigid punch. In the same year, Charpentier [4] investigated the influence of the punch curvature on the stretching limits of steel sheets. Charpentier suggested that, as the sheet curvature increases, resulting in larger strain gradients, the limit strains also increases. He also demonstrated that, the limit strains increase with increasing punch curvature $(1 / \mathrm{R})$ at a constant material thickness by varying the nose radii of the punch during the experiments as in [5].

The use of advanced high strength steels in the following years made it more relevant and the influence of bending was more notorious. Some authors have shown such as, Col [6], Vallellano et al. [5], and Till et al. [7] that the formability, determined for a sheet, increases with decreasing radii to thickness ratio. Till et al. showed that increased formability was seen especially for Advanced High Strength steels. More recent investigations predicted the necking behaviour of a metal sheet under combined stretching and bending by FEM simulations and an analytical method [8]. In FEM simulations for stretch-bending no necking was observed. In bend stretching the prebending promotes neck initiation during the subsequent stretching phase.

In one of the recent studies done by Fictorie et al [2], and made available to a wider public through $[11,12]$ two new setups were developed for a set of different punch diameters $(20 \mathrm{~mm}-50 \mathrm{~mm})$. They were tested with four different materials, and the main goal was to compare this data with the experimental information from the standardized Nakazima test $(100 \mathrm{~mm})$. In that study, the formability of an aluminum alloy and mild steel was improved by increasing the curvature of the punch and its especially clear influence in the plane strain region. Part of the newest work in this matter was realized by Hudgins et al. [9]. They developed an analytical model based on mechanics and material properties to predict instability expressed by maximum applied tensile stress as a function of die radius normalized by sheet thickness $(\mathrm{R} / \mathrm{t})$.

Forming limit curves are usually determined for membrane type deformations when FEM simulations are employed. Furthermore, the limit curves acquired seem to underestimate the limit values of strains and one reason may attributed to the effect of the thickness stress in the material. Also, the influence of simultaneous bending deformation on the forming limits has attracted renewed attention, and for that reason it is necessary that the determination of the forming limits curve should use solid elements in thickness instead of shell elements.

\section{FORMING LIMIT CURVE DESCRIPTION}

The main focus of this research is to derive a stability model which can encounter the enhanced formability obtained when simultaneous bending and stretching is applied to a sheet metal with $1.4 \mathrm{~mm}$ in thickness of HCT600x steel with a $20 \mathrm{~mm}$ and $50 \mathrm{~mm}$ punch. In FIGURE 1a, a schematic of the sensitivity of the material to different punch radii during the Nakazima Test is depicted. It was concluded from previous work [2], and literature review that some factors could be responsible for the improvement of formability in relation to bending in terms of the Nakazima Test. 


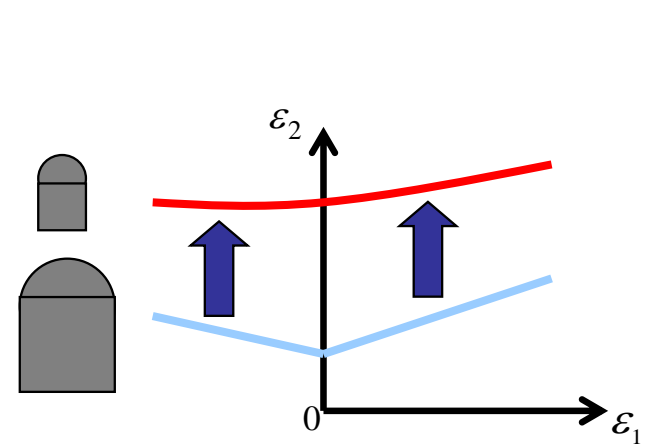

FLC

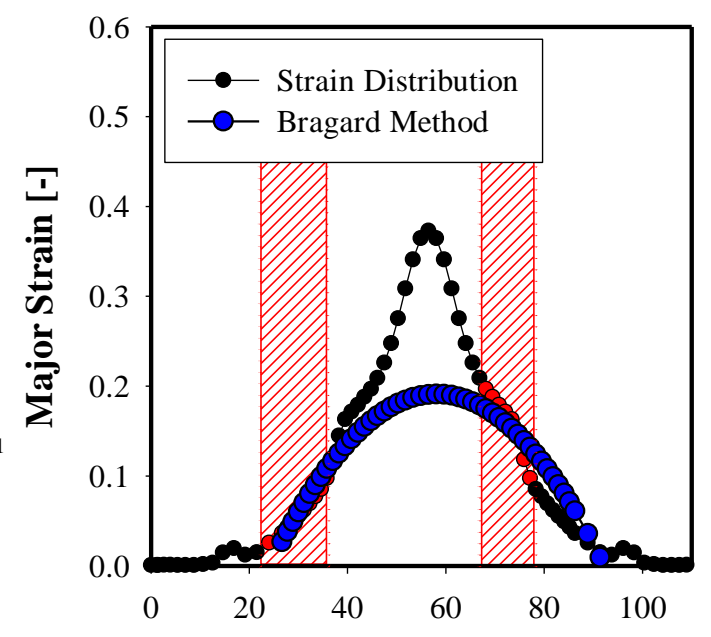

b) a)

FIG
True Distance [mm]

However, the previous FEM simulations of the process were not sufficient to fully capture the essence of the forming operation due to certain limits of the model itself. Summarizing these effects that could play a dominant role in the observed enhanced formability we encounter the following considerations: a) Pressure on the inside of the sheet, b) Friction between blank and punch, and c) Less ductile fracture behavior.

For the FLC determination it is assumed that necking is one of the main failures in terms of formability. It is known that the FLC shows under which strain conditions the material becomes plastically unstable and consequently starts necking. In a tensile test necking will first be diffuse and then localized to promote fracture. In sheet metal forming mostly diffuse necking cannot occur and localized necking is the only necking mechanism. In a previous research to determine necking the Bragard method was used, see Figure 1b. From the strain distribution the necked points are eliminated and the necking point is reconstructed by the use of an inverse parabolic function [11, 12]. Furthermore, the application of this method has shown that the fitting window to determine the limit strain fail to remain in the contact zone between the blank and the punch, which means that only the contribution of the stretching part will be considered and not the combination of stretching and bending.

\section{D FINITE ELEMENT MODEL OF NAKAZIMA TEST}

In order to improve the results from the previous research and to consider some of the assumptions made in the past, a solid model would be used to encounter all the through thickness effects. A solid model would also lead to some disadvantages such as the number of elements needed and the increase in the overall computation time. The FEM simulation of the Nakazima Test was realized with the software ABAQUS/Standard and the elements were defined as C3D8R with enhanced hourglass control. One of the influencing factors in the simulations is the friction between the bottom part of the blank and the punch. It is commonly assumed as a frictionless interaction, but in this study three different friction coefficients $(0,0.01$, 
$0.05)$ were employed and compared. The representation of the friction between the following interactions: a) workpiece-die, and workpiece-blankholder is more straightforward since the material should remain clamped. For interaction a, the friction coefficient commonly used for metal to metal of 0.12 was used. Since the area of contact of the blankholder is usually fully serrated it is expected to have a relatively high friction coefficient, in this case a value of 2 was set. The required blankholder force was varied between $100-200 \mathrm{kN}$ for the $20 \mathrm{~mm}$ (FLC20), and $200-300 \mathrm{kN}$ for the $50 \mathrm{~mm}$ (FLC50) punch simulations. The sample design for both punch dimensions was developed in [2] and based on the original size/shape of the samples used for the original Nakazima test of $100 \mathrm{~mm}$ punch (FLC100). The samples were scaled to fit the experimental setup and the two different punch diameters $(20-50 \mathrm{~mm})$. A summary of all the sample parameters can be found in [2].

During the first attempt to obtain a stable FEM simulation, Abaqus/Standard was used. The specimen was $1.4 \mathrm{~mm}$ thickness and the material properties for HCT600X $+Z$ (often referred to as DP600) were obtained from literature [10]. The yield locus description is based on Hill's 48 , and the Bergström-van Liempt hardening equation. The description of the hardening equation and the parameters used in the simulations can be found in [1].

\section{SIMULATION RESULTS}

In order to asses when the material becomes unstable, a criterion from the previous research to determine the necking point was used, see Eq. (1).

$$
\frac{\dot{\varepsilon}_{\text {top }}}{\dot{\varepsilon}_{\text {top-/+4elements }}} \geq 20
$$

The criterion is based on the element where the strain rate is localized for the top and bottom surface in the history elements.
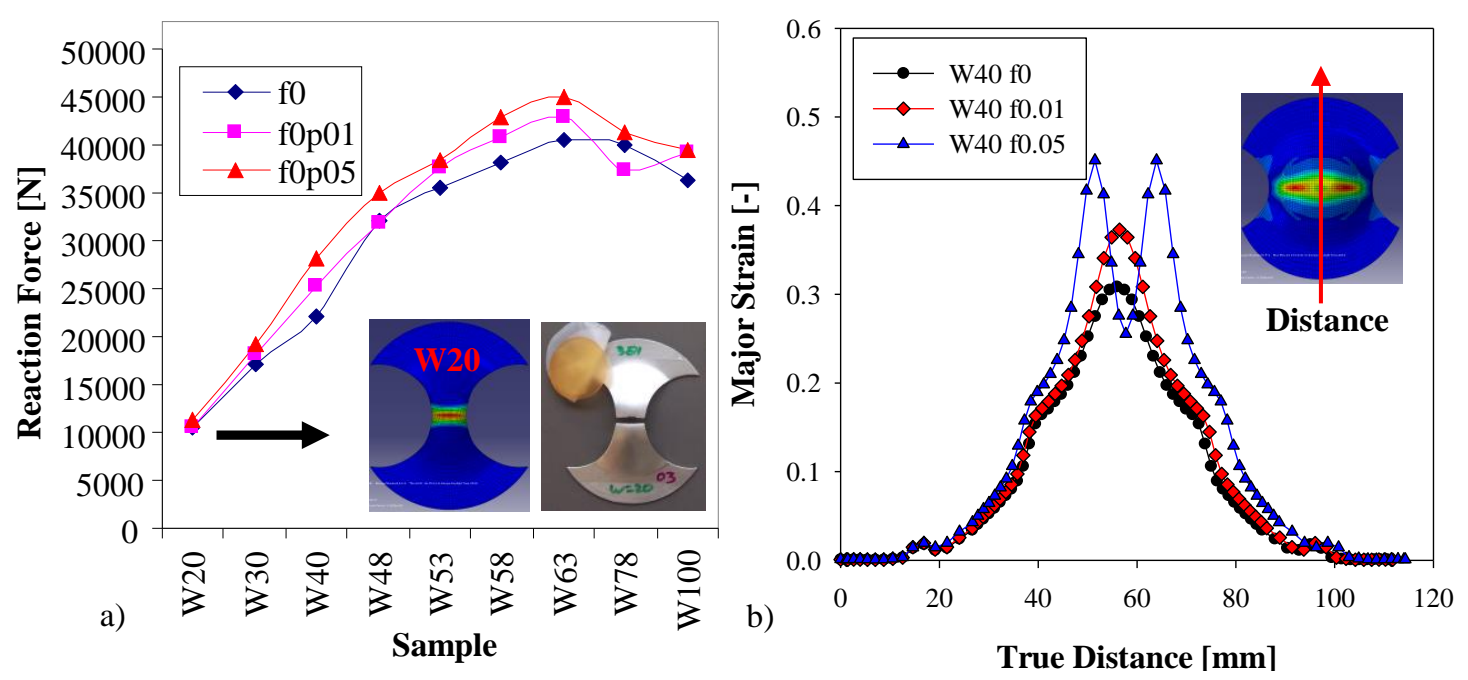

FIGURE 2. a) Force vs. displacement curves $(20 \mathrm{~mm})$ b) Effect of friction on strain rate localization. 
A comparison was made for the strain rate values over time for the top elements, and the bottom elements in the region were the crack in the experiments usually appears. Different strain paths were followed to be able to determine each point of the FLC. Using a higher coefficient of friction between the punch, and the bottom of the blank (contact zone), it will result in higher reaction forces as shown in FIGURE 2a for the case of a $50 \mathrm{~mm}$ punch. It is clear that selecting a higher friction coefficient such as 0.05 promotes that the material to localize away from the top of the dome, see FIGURE 2b. In order to get the fracture on the top of the specimen in experiments, a rubber pad and Teflon layers are used. Since, considering a coefficient of friction equal to zero for the simulations is unrealistic, a value of 0.01 is probably near to the actual value during the experiment. Moreover, the use of a rubber pad will introduce a force pointing away from the top. In a model such as the current in which the rubber pad is omitted, it could be thought of as negative friction.

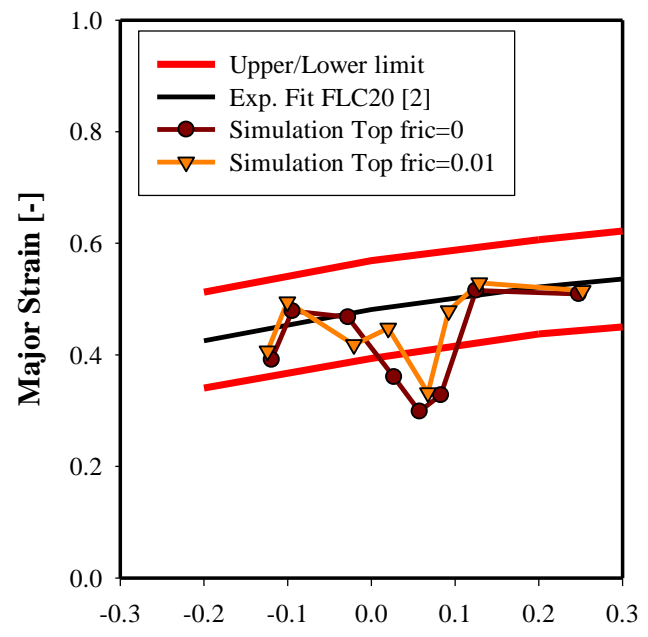

a)

Minor Strain [-]

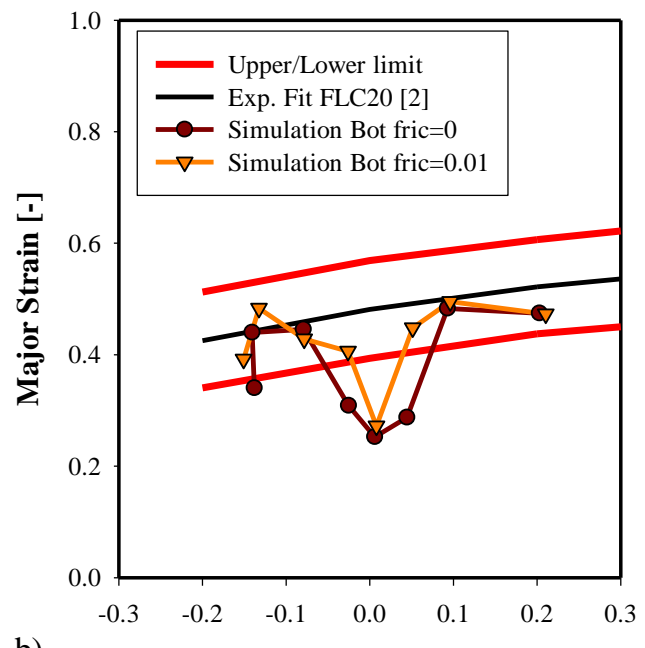

b)

Minor Strain [-]

FIGURE 3. FLC-20 Experimental and simulation results: a) Top elements and b) Bottom Elements.

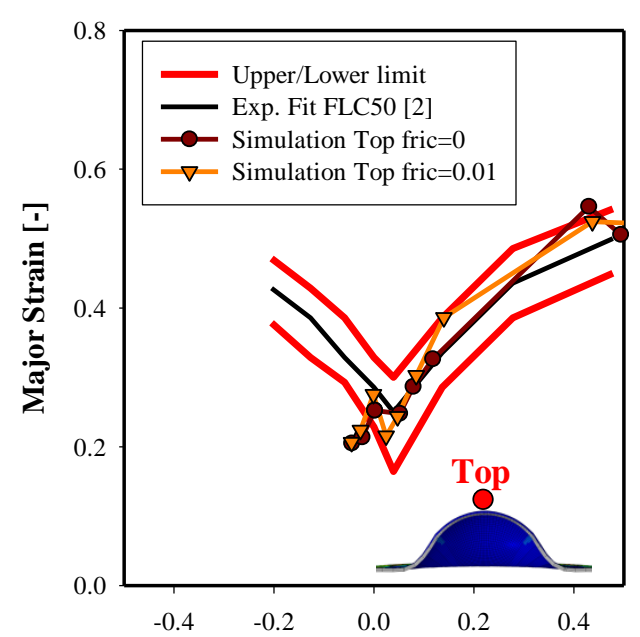

a)

Minor Strain [-]

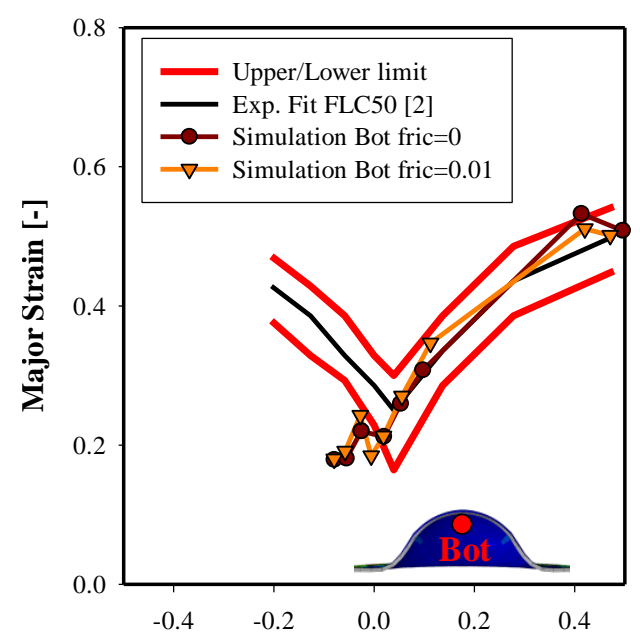

b)

Minor Strain [-]

FIGURE 4. FLC-50 Experimental simulation results: a) Top elements and b) Bottom elements. 
In FIGURE 3, and FIGURE 4, a comparison is made between the simulations results of the $20-50 \mathrm{~mm}$ punch, and the experimental trend line fitted from a previous research [2] for the top elements (a), and bottom elements (b). In these figures, the experimental data fit (black solid line) is bounded by the upper limit and lower limits (red dotted line) with a 95\% confidence. It can be seen that the simulations (FIGURE $3 \mathrm{a}$ and $3 \mathrm{~b}$ ) with zero friction underestimate the forming limits for the region near plane strain. It is also clear that the FLC does not follow the traditional $V$ shaped, but the FEM simulations are capable to predict with reasonable accuracy the strain limits when friction is included. Comparing FIGURE 3 and FIGURE 4, it can be seen how using a smaller punch in the experiments it increases the amount of bending on the forming operation, hence promoting an enhancement in the formability limits. The simulations from FIGURE $4 \mathrm{a}$ and FIGURE $4 \mathrm{~b}$ are in good agreement for the right hand side of the FLC, but tend to deviate in the region of uniaxial strain. This effect is still being investigated and further work is necessary to determine the reason.

\section{CONCLUSIONS}

In this work, the numerical determination and comparison with experimental data for the Nakazima test with two different punch diameters was accomplished. The effect of bending was pointed as critical for the appropriate determination of the formability limits through FEM simulations. In terms of the $50 \mathrm{~mm}$ punch the simulations are in reasonable agreement with the experiments, but more work is necessary for the $20 \mathrm{~mm}$ punch.

\section{ACKNOWLEDGMENTS}

This research was carried out under project number M22.1.09335 in the framework of the Research Program of the Materials innovation institute M2i. The University of Twente and Tata Steel RD\&T are gratefully acknowledged for providing the technical expertise and experimental data.

\section{REFERENCES}

1. H. Vegter, and A.H. van de Boogaard, International Journal of Plasticity, 22, 557-580 (2006).

2. E. Fictorie, Master Thesis, University of Twente, Enschede, Netherlands, 2009.

3. Ghosh, 1974 A.K. Ghosh, Metall. Mater. Trans. B 5, 1607-1616 (1974).

4. P. L. Charpentier, Met.Trans. A, 6A, 1665-1669 (1975).

5. C. Vallellano, Numisheet 2008, Interlaken, Switzerland, 85-90 (2008).

6. A. Col, "FLCs: are we at a turn?", 2005 IDDRG Conference, Besançon, France, 2005

7. E.T. Till, E. Berger, and P. Larour, 2008 IDDRG Conference, Olofström, Sweden, 2008.

8. N.E. de Kuijf, Master Thesis, Eindhoven University of Technology, 2008.

9. A.W. Hudgins, D.K. Matlock, J.G. Speer, and C.J. Van Tyne, Journal of Materials Processing Technology, 210, 741-750 (2010).

10. Horn ten C.H.L.J., Corus RD\&T Ijmuiden, Reference source: 136556, 2008.

11. E. Fictorie, A.H. van den Boogaard, E.H. Atzema, International Journal of Material Forming, Springer Paris, ISSN 1960-6206, 3 (1), 2010, 1179-1182.

12. E.H. Atzema, E. Fictorie, A.H. van den Boogaard \& J.M.M. Droog, 2010 IDDRG Conference, Graz, Austria, 2010. 